\title{
ARTERY OF HAAS-ITS ORIGIN AND COURSE: A CLINICAL PERSPECTIVE
}

\author{
Vidyashambhava Pare *1, Harsha C.R. ${ }^{2}$, Roopa Kulkarni ${ }^{3}$, Sheela G. Nayak ${ }^{4}$.
}

${ }^{* 1}$ Professor and Head, Department of Anatomy, K.V.G. Medical College and Hospital, Kurunjibagh, Sullia, Dakshina Kannada, India.

${ }^{2}$ Assistant Professor, Department of Anatomy, K.V.G. Medical College and Hospital, Kurunjibagh, Sullia, Dakshina Kannada, India.

${ }^{3}$ Principal and Professor of Anatomy, K.V.G. Medical College and Hospital, Kurunjibagh, Sullia, Dakshina Kannada, India.

${ }^{4}$ Dean (Academics), K.V.G. Medical College and Hospital, Kurunjibagh, Sullia, Dakshina Kannada, India.

\section{ABSTRACT}

Introduction: Human heart is the organ which supplies blood to all tissues. But the heart itself requires proper nutrition to conduct impulses for the contraction of the heart normally. For the efficient functioning of the conducting system, the nutrition to it is essential. One of the components of the cardiac conducting system is atrioventricular node. The artery to the atrioventricular node also called as artery of Haas which arises from the right coronary artery in majority of cases. In some cases it arises from the left circumflex artery. Apart from the origin, the angle that the artery makes with its parent artery at the site of origin is clinically important, as this angle can determine the amount of circulation and nourishment.

Materials and Methods: Sixty heart specimens obtained from the Department of Anatomy, Mysore Medical College, Mysore, over a period of two years, were studied by dissection method (37 hearts), corrosion cast (16 hearts), and arteriography (7 hearts).

Observation and Results: The origin and the angle at the origin with parent artery were studied. In $80 \%$ of hearts the atrioventricular nodal artery arose from right coronary artery, in $8.3 \%$ of cases it arose from left circumflex artery. In $6.6 \%$ cases it arose from both right coronary and left circumflex arteries. In $5 \%$ of cases there was absence of a separate atrioventricular nodal artery. The angle it made with the parent trunk was observed in 57 hearts. In $66.1 \%$ of cases the artery was making obtuse angle, in $30.5 \%$ of cases it was at right angles and in $03.3 \%$ of cases it was making an acute angle at the site of origin from the parent trunk. There were two atrioventricular nodal arteries arising from right coronary artery which anastomosed with each other.

Conclusion: The atrioventricular nodal artery is the main nourishing channel for the atrioventricular node of the conducting system of heart. The variations in origin, course and the angle it makes with the parent trunk at its origin, play an important role in the functioning of heart. No references were available about the angle of atrioventricular nodal artery at its origin from the parent trunk, which is the original work.

KEY WORDS: Atrioventricular Node, Atrioventricular Nodal Artery, Artery Of Haas, Conducting System, Coronary Arteries.

Address for Correspondence: Dr. V.S. Pare, Professor \& Head, Department of Anatomy, K.V.G. Medical College \& Hospital, Sullia, Dakshina Kannada-574327, India.

Mobile: 9448460498, 9901730398. E-Mail:vs_pare@yahoo.co.in

\section{Access this Article online}

\section{Quick Response code}

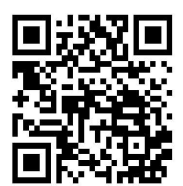

DOI: $10.16965 /$ ijar.2017.174

Web site: International Journal of Anatomy and Research

ISSN 2321-4287

www.ijmhr.org/ijar.htm

Received: 07 Mar 2017

Peer Review: 08 Mar 2017

Revised: None
Accepted: 15 Apr 2017

Published (O): 30 Apr 2017

Published (P): 30 Apr 2017 


\section{INTRODUCTION}

The artery of Haas, is the artery to Atrioventricular node. In majority of cases this artery arises from right coronary artery. In 1911, Haas studied extensively, the atrioventricular nodal artery and its branches, in human, canine and bovine hearts. Therefore it is called the ARTERY OF HAAS. [1]. Human heart beats continuously at approximately 70 cycles per minute, from birth to death. This helps in the maintenance of the blood supply to tissues of the body. Depending upon the physiological demands of organs and systems, the rate and the stroke volume vary. For this cardiac activity, the integrity and normal functioning of the conducting system of the heart is very important. The atrioventricular node is one of the components of the conducting system of heart. The final termination of this conducting system is seen ending on the cardiac muscle tissue of atrial walls, septal walls, papillary muscles and ventricular walls. The atrioventricular node is an atrial structure of conducting system of heart and is located in the region of triangle of Koch. Except the sinoatrial node, all the other components of conducting system of heart are continuous with each other. The nutrition to the conducting system of heart is one of the important factors for its normal functioning. The atrioventricular node is supplied by the branches of right coronary artery in about $80 \%$ to $90 \%$ of cases and from left circumflex artery in about $10 \%$ to $20 \%$ of cases $[2,3]$. When right coronary artery is involved in supplying the atrioventricular node, it usually arises from one of the septal branches, and it is normally the largest posterior septal branch, which is usually the first and arises from the inverted loop of right coronary artery at the crux. It supplies in about $80 \%-90 \%$ of cases. If the left coronary artery is involved in supplying the atrioventricular node, it is usually a terminal branch of circumflex artery that arises near the crux of the heart. This is seen in about $10 \%$ to $20 \%$ of cases. [2-4].

Embryology of coronary arteries and their branches: The embryonic blood vessels, during development, appear in conjunction with other rudiments, where there is need for the blood supply. The blood vessels develop prior to the establishment of circulation. The initial phase of nourishment and drainage of the predominantly spongy wall of the heart is by the intertrabecular sinusoids. The coronary arteries develop in situ and later get connected with aortic buds. [5-8]. The coronary arteries and their branches are affected in atherosclerosis. It is characterised by deposition of lipid and accumulation of macrophages in the intimal layer of the vessel wall. The plaque formation may cause occlusion of the lumen of the artery and reduce the flow of blood. The plaques may rupture and thrombus is formed which leads to acute occlusion. This may lead to infarction of the nodal tissue or the myocardium depending upon the artery and the level at which the obstruction is present. The detachment or rupture of the plaque may be due to fatigue within the fibrous cap or, when the lipid content is more than $40 \%$ of the plaque composition [2]. The damage is more severe because the coronary arteries and their branches are physiological end arteries. Due to the damage of the nodal tissue, caused by loss of blood supply, there may be abnormalities in cardiac conduction and rhythm. The abnormalities of the conducting system are arrhythmias, tachycardia or bradycardia. Occasionally conduction abnormalities are caused by multifocal Purkinje fibre tumours or benign congenital polycystic tumours of atrioventricular node. In case of long standing hemodynamic problems or effects of previous surgery for patients with congenital heart defects, there will be conduction abnormalities [2].

The surgical procedures like cardiac transplantation, artificial heart and coronary bypass, with their excellent prognostic value has induced interest in the present work.

\section{MATERIALS AND METHODS}

Sixty human hearts were collected from the Department of Anatomy, Mysore Medical College, Mysore, from 1983 to 1985. The age and sex of each case were noted. Age varied from few months to 75 years. There were 31 hearts belonging to males and 29 hearts belonging to females. The cause of death was not known. The hearts were washed thoroughly to remove clots by using saline and $40 \%$ Borax solution. The coronary ostia in the ascending aorta were identified and carefully dissected. 
In 37 hearts, the arteries were studied by meticulous dissection method after embalming in formalin. 16 hearts were studied by preparing corrosion casts using butyl butyrate and 07 hearts were studied radiographically (arteriography) by injecting radio opaque material, which consisted of finely triturated $20 \%$ aqueous solution of red lead (15 gm \%) and starch ( $5 \mathrm{gm}$ $\%)$, into the coronary arterial system. These 07 hearts were embalmed in $10 \%$ formalin and preserved in $07 \%$ formalin solution.

\section{OBSERVATIONS}

Table 1: Showing the origin of atrioventricular nodal artery from various sources.

\begin{tabular}{|c|c|c|c|c|c|c|c|}
\hline S. No & \multirow{2}{*}{ Type } & \multirow{2}{*}{ Description Parent artery } & \multicolumn{3}{|c|}{ Method of study } & \multirow{2}{*}{ Total } & \multirow{2}{*}{$\%$} \\
\cline { 5 - 7 } & & Dissection & Corrosion cast & Arteriography & & \\
\hline 1 & A & Rt. Coronary artery & 30 & 13 & 5 & 48 & $80 \%$ \\
\hline 2 & B & Lt. circumflex artery & 3 & 1 & 1 & 5 & $8.30 \%$ \\
\hline 3 & C & $\begin{array}{c}\text { From Rt. coronary artery \& Lt. } \\
\text { circumflex artery }\end{array}$ & 2 & 1 & 1 & 4 & $6.60 \%$ \\
\hline 4 & D & Absence of A-V nodal artery & 2 & 1 & NIL & 3 & $5 \%$ \\
\hline
\end{tabular}

Table 2: Classification of atrioventricular nodal artery depending on the angle it makes with the parent trunk of origin. This observation was made only in 57 hearts. In two hearts, there were two arteries, one was arising at right angles to the parent artery and the other branch was arising at obtuse angle. (Figure No 6). Therefore the total number of observations are made in 59 specimens.

\begin{tabular}{|c|c|c|c|c|c|c|}
\hline \multirow{2}{*}{ S.No. } & \multirow{2}{*}{ Angle of origin } & \multicolumn{3}{|c|}{ Method of study } & \multirow{2}{*}{ Total } & \multirow{2}{*}{$\%$} \\
\cline { 3 - 5 } & & Dissection & Corrosion cast & Arteriography & & \\
\hline 1 & Acute & 1 & 1 & - & 2 & $3.30 \%$ \\
\hline 2 & Right angle & 11 & 5 & 2 & 18 & $30.50 \%$ \\
\hline 3 & Obtuse & 25 & 9 & 5 & 39 & $66.10 \%$ \\
\hline
\end{tabular}

Table 3: Comparison of the origin of atrioventricular nodal artery with other authors.

\begin{tabular}{|c|l|c|c|c|}
\hline \multirow{2}{*}{ S.No } & \multirow{2}{*}{ Author } & \multicolumn{3}{|c|}{ Origin of the atrioventricular nodal artery } \\
\cline { 3 - 5 } & $\begin{array}{c}\text { Right coronary } \\
\text { artery }\end{array}$ & $\begin{array}{c}\text { Left circumflex } \\
\text { artery }\end{array}$ & $\begin{array}{c}\text { Both coronary } \\
\text { arteries }\end{array}$ \\
\hline 1 & James T.N. (1961) & $86 \%$ & $12 \%$ & $2 \%$ \\
\hline 2 & J. T. Roberts (1961) & $92 \%$ & $8 \%$ & NIL \\
\hline 3 & Baroldi and Scomazzoni (1956) & $\begin{array}{c}\text { Common (No \% } \\
\text { reported) }\end{array}$ & $\begin{array}{c}\text { Rare (No \% } \\
\text { reported) }\end{array}$ & NIL \\
\hline 4 & Hutchinson (1978) & $80 \%$ & $20 \%$ & NIL \\
\hline 5 & Present study & $80 \%$ & $8.30 \%$ & $6.60 \%$ \\
\hline \multicolumn{4}{|c|}{ In 05\% of cases the artery was absent in the present study } \\
\hline
\end{tabular}

After visualizing the course of the artery supplying the atrioventricular node, the observations were carried out under the following categories:

\section{Origin of atrioventricular nodal artery}

2. Angle of origin from the parent trunk

1. The origin of atrioventricular nodal artery was further classified into Type A, B, C and D

2. The angles observed were:

a) Acute angle (b) right angle and (c) obtuse angle

Fig. 1: The atrioventricular nodal artery arising from the right coronary artery $(A)$ viewed from the postero inferior aspect of the heart.

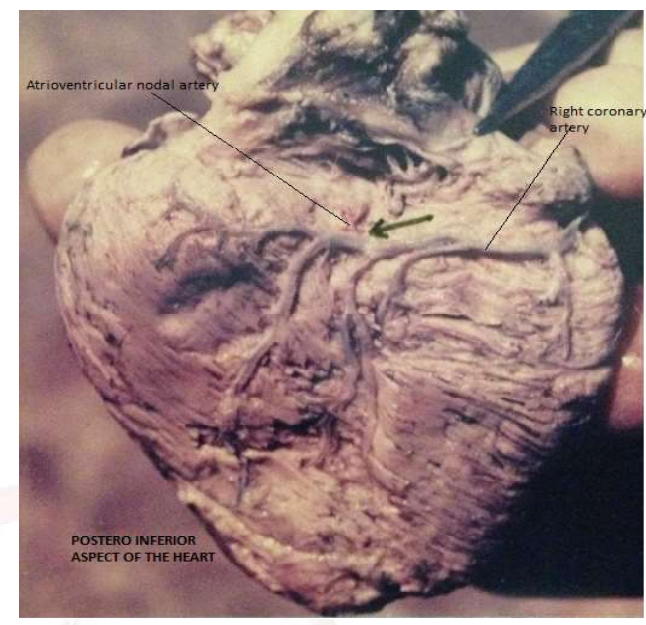

Fig. 2: Arteriography of coronary arteries and their branches. The atrioventricular nodal artery arising from left circumflex artery (B).

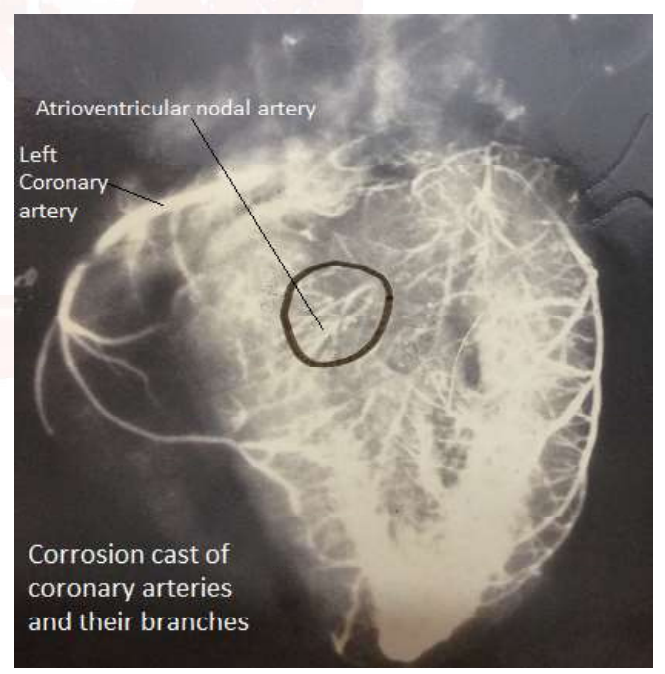

Fig. 3: The atrioventricular nodal artery arising from both right coronary artery and left circumflex artery (C). Both arteries are arising near the crux of the heart.

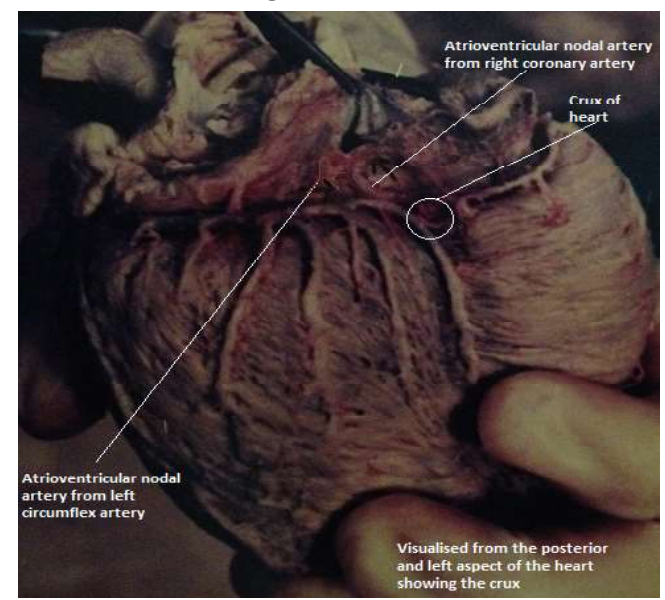


Fig. 4: There was no separate artery to the atrioventricular node (D). Probably the arterial supply was from the neighbouring arteries supplying the heart.

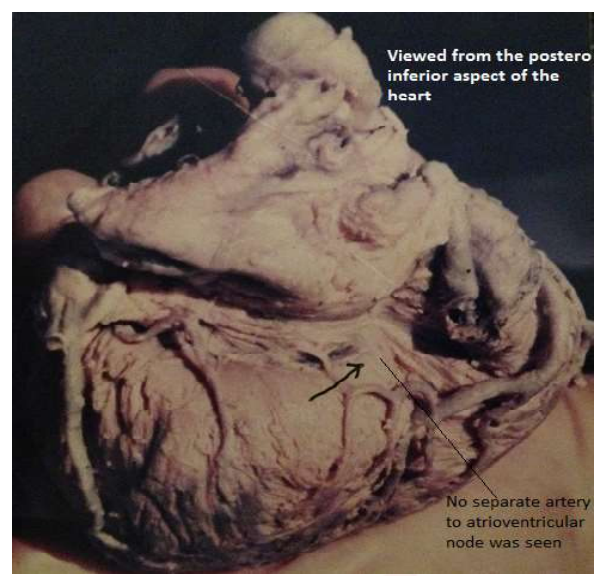

Fig. 6: The atrioventricular nodal artery arising from the right coronary artery making right angle with its parent trunk. Arrows showing atrioventricular nodal artery.

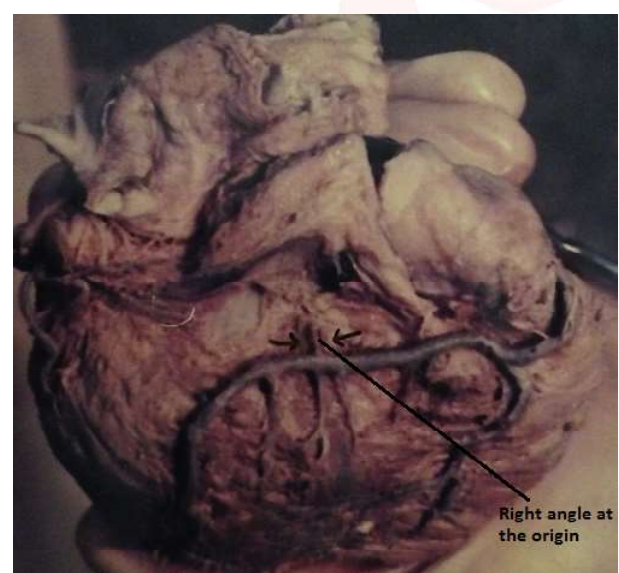

Fig. 8: The atrioventricular nodal artery arising from right coronary artery making obtuse angle with the parent artery. (c). Enlarged picture of Figure 7.

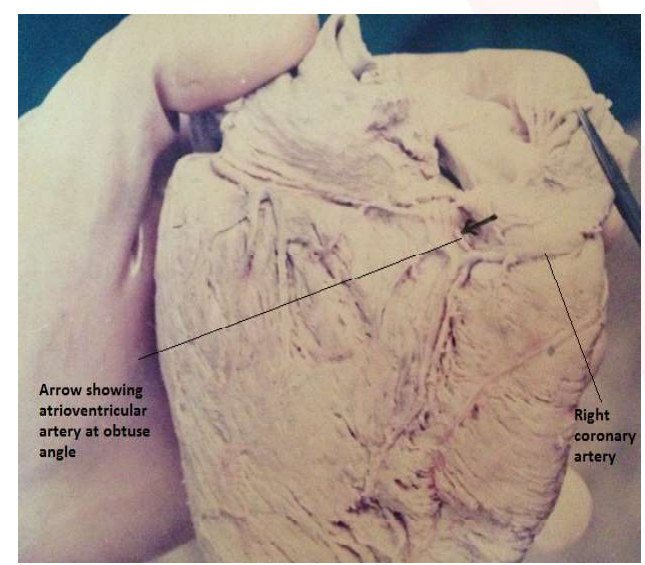

\section{DISCUSSION}

The atrioventricular node is smaller than the sinoatrial node, situated deep to endocardium in the triangle of Koch. It was discovered by Tawara in 1906. It measures about $8 \mathrm{~mm}$ anteroposteriorly, $3 \mathrm{~mm}$ vertically and $01 \mathrm{~mm}$ transversely. The atrioventricular node is supplied by artery
Fig. 5: The atrioventricular nodal arteries arising from right coronary artery, one making right angle and the other making obtuse angle with its parent trunk.

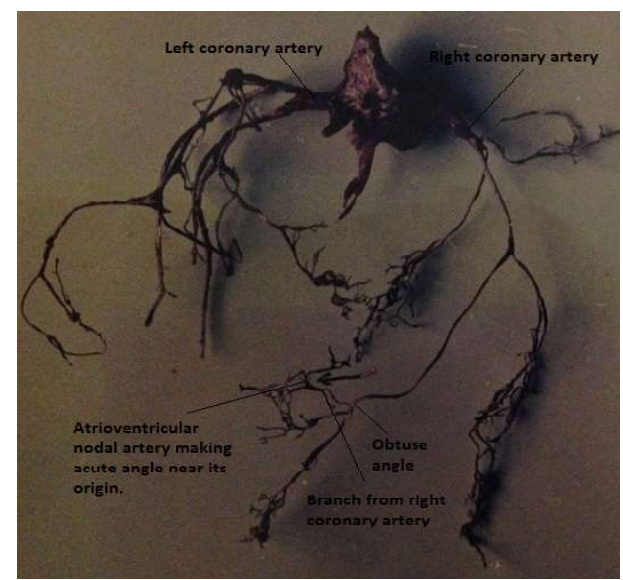

Fig. 7: The atrioventricular nodal artery arising from right coronary artery making obtuse angle with the parent artery (c).

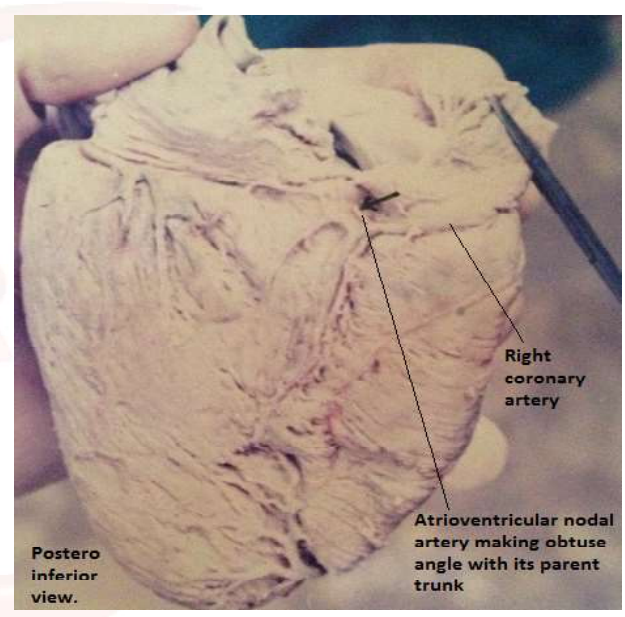

of Haas which is the atrioventricular nodal artery. In 1911, Haas studied this artery extensively in human, canine and bovine hearts, hence called the artery of HAAS. [2, 1]. The coronary artery disease is one of the major causes of mortality. The morbidity is due to the varied origin and course of the coronary arteries which is due to the developmental reasons. The variations in the origin of coronary arteries and their branches are due to the developmental process of the arterial system. It is believed that the coronary arteries and their branches develop from two anlagen, one is proximal, which is from the truncus arteriosus that arises as two buds and the other is distal, at the sub-pericardial region as plexus of capillaries. These anlagen grow towards each other and make communications and form coronary arteries and their branches [9]. The cells that make up the coronary system arise outside the heart. The variation in the patterning of coronary arteries 
represents a complex system for analysis of regulation of cell fate determination, cell and epithelial migration and epithelial/ mesenchymal transition. All this happens without the drainage of blood into the lumen of the heart [5]. Thus, the mode of development of coronary arteries and their branches helps us to explain the variations in the origin and course of them. These variations in the branching and course of the coronary arteries, which supply the myocardium and conducting system of the heart may lead to myocardial ischemia, malignant arrhythmias and sudden cardiac death [10].

In the present study, the atrioventricular nodal artery arose from right coronary artery in about $80 \%$ of cases (Table 1, Figure 1 ). Our values coincided with the values of Hutchinson which was $80 \%$. The observations made by James T.N showed origin of atrioventricular nodal artery from right coronary artery in $86 \%$ and studies conducted by J. T. Roberts showed origin of atrioventricular nodal artery from right coronary artery in $92 \%$ of cases (Table 3 ). In the present study, in about $8.3 \%$ of cases the atrioventricular nodal artery originated from Left circumflex artery (Table 1, Figure 2) which coincided with the observations made by Joseph (08\%) whereas studies conducted by James T.N. showed $12 \%$ and studies conducted by Hutchinson showed $20 \%$ (Table 3 ). In $6.6 \%$ of cases, the atrioventricular nodal artery originated from two arteries, i.e., from right coronary artery and from left circumflex artery (Table 1, Figure 3 ). The observations made by James T.N. showed the origin of atrioventricular nodal artery from both right and left coronary arteries in about $2 \%$ of cases. The artery to atrioventricular node was absent in $5 \%$ of cases in the present study. This was not observed by previous workers. (Table 3, Figure 4). Probably in these hearts, the atrioventricular nodal artery was derived from the neighbouring arteries which could be from the finer branches of the coronary arteries. [11, $3,4]$.

The other observation made in the present study was, regarding the angle of origin, the atrioventricular nodal artery making with its parent trunk. The artery either makes an acute angle, right angle, or an obtuse angle at its origin from its parent trunk. The atrioventricular nodal artery made acute angle in about $03.35 \%$ of cases (Table 2, Figure 5), right angle in about $30.5 \%$ of cases (Table 2, Figure 6), and in $66.1 \%$ of cases the artery originated at an obtuse angle from the parent trunk (Table 2, Figures $7 \& 8$ ). The angle of origin is very important, because, if the angle is acute, there may be reduced flow of blood if the artery is coursing in opposite direction to the parent artery. If there are obstructive diseases of the coronary arteries, such as atherosclerosis, there would be obstruction leading to reduced blood flow and ischemia to the A-V node leading to the death of the tissue and heart block [2]. The angle of origin, at which the atrioventricular nodal artery makes with its parent trunk, though very important, has not been observed by many of the workers.

\section{CONCLUSION}

The atrioventricular node is smaller than the sinoatrial node, situated deep to endocardium in the triangle of Koch. Its arterial supply was extensively studied by Haas in 1911. The artery of Haas, which is the atrioventricular nodal artery arises from the right coronary artery in $80 \%-90 \%$ of hearts, and in the remaining (10\% - 20\%), it arises from the circumflex branch of left coronary artery, or from both right coronary and left circumflex arteries. In the present study of sixty hearts, 37 were subjected to simple dissection, 16 hearts were studied by corrosion cast method, and 07 specimens were studied by arteriography by injecting radio opaque dye into the coronary arteries. The atrioventricular nodal artery was arising from right coronary artery in $80 \%$ of cases, from left circumflex artery in $8.3 \%$ of cases. It originated from both right coronary artery and left circumflex artery in $6.6 \%$ of cases. The artery to the atrioventricular node was not seen in $5 \%$ of cases. Probably there were minute arteries derived from neighbouring arteries which were not visible to the naked eye. The angle at the origin from the parent trunk was also studied in which there was acute angle in $3.3 \%$, right angle in $30.6 \%$ and obtuse angle in $66.1 \%$ of hearts. The angle of atrioventricular nodal artery at its origin with the parent trunk plays a very important role in the blood flow and any obstruction or lack of pressure in the arteries may leads to 
impairment in the nourishment to the atrioventricular node and cause complete or partial heart block. Hence the present study tries to create a possible new approach for research, in preventing conduction block due to vascular causes.

\section{Conflicts of Interests: None}

\section{REFERENCES}

[1]. L. G. Van der Hauwaert, R. Stroobandt, and L. Verhaeghe, Arterial blood supply of the atrioventricular node and main bundle. British Heart Journal, 1972;34:1045-1051.

[2]. Susan Standring; Gray's Anatomy, Ch. Thorax, Section 7; chapter 56, Heart and great vessels. 2008, $40^{\text {th }}$ edition. Elsevier Churchill Livingstone. Page no. 977-981.

[3]. James T.N., Anatomy of Coronary arteries in Health and disease. Circulation, 1965;32:1020-1033.

[4]. Hutchinson M.C.E., A Study of Atrial Arteries in Man; Journal of Anatomy; 1978;125: 39-54.

[5]. David E. Reese, Takashi Mikawa and David M. Bader; Development of Coronary Vessel System. Circulation Research; 2002;91:761-768.
[6]. Adriana DM Villa, Eva Sammut, Arjun Nair, Ronak Rajani, Rodolfo Bonmini and Amedeo Chiribiri, Coronary artery anomalies overview: The normal and the abnormal. World J. Radiol. 2016 June 28;8(6):537-555.

[7]. PITT, B. Interarterial coronary anastomoses. Occurance in normal hearts and in certain pathologic conditions. Circulation, 1959;20:816-22.

[8]. Baroldi G, Mantero O, Scomazzoni G. The collaterals of the coronary arteries in normal and pathologic heart. Circulation Research. 1956;4:223-9.

[9]. Giuseppe Conte, Antonio Pellegrini. On the development of coronary arteries in human embryos, stages 14 - 19, Anatomy and Embryology, May 1984;169(2):209-218.

[10]. Gentian Lluri, Jamil Aboulhosn. Coronary arterial development: A review of Normal and Congenitally Anomalous Patterns. Clin. Cardiaol, 2014;37(2): 126-130.

[11]. J.T.Roberts, S.D. Loube. Congenital single coronary artery in man; report of nine new cases, one having thrombosis with right ventricular and atrial (auricular) infarction. Am. Heart J. 1947 Aug;34(2):188208.

How to cite this article:

Vidyashambhava Pare, Harsha C.R., Roopa Kulkarni, Sheela G. Nayak. ARTERY OF HAAS- ITS ORIGIN AND COURSE: A CLINICAL PERSPECTIVE. Int J Anat Res 2017;5(2.1):3771-3776. DOI: 10.16965/ijar.2017.174 